\title{
Poverty in Africa and the Forces of Change: Reflections on Rawls Difference Principle
}

\author{
Moses O. Aderibigbe \\ School of Sciences, General Studies Department, Federal University of Technology, Akure, Nigeria \\ Email: mosesaderibigbe@yahoo.com
}

Received May 23 ${ }^{\text {rd }}$, 2012; revised June $27^{\text {th }}$, 2012; accepted July $11^{\text {th }}$, 2012

\begin{abstract}
Africa is no doubt one of the continents endowed with resources necessary for the achievement of development in all areas. The pre-colonial era as crude as being described, was to a large extent characterized by values for self sustenance. However, the crises being witnessed in Africa as it manifest in hunger, lack and scarcity over these years have been on one hand, argued to have resulted from the contact Africa had with the external forces of colonialism. These forces as claimed ushered in unbridled economic system with its implications on value system of brotherhood, reciprocity and fraternity among others. On the other hand, the internal forces which manifest in corruption, mismanagement and bad leadership, have totally grounded the development to a halt. This paper critically examines these forces of change, with the aim of identifying the missing link and attempt to suggest ways towards charting a new course in order to regain the values. The paper applies John Rawls Difference Principle as a theoretical framework, capable of ensuring that benefits and burdens are fairly distributed for the advantage of every one, more especially the less privileged in society. This would enhance the attainment of a stable social order as it promotes the ideals of reciprocity and fraternity in society.
\end{abstract}

Keywords: Poverty; Colonialism; Leadership; Rawls; Values

\section{Introduction}

This essay focuses on the problem of poverty and the forces of change in Africa. The paper attempt to prove that there are certain core values such as brotherhood, fraternity and reciprocity, which among others made Africa and its people self sufficient in the generation and distribution of the basic necessities of life. The inability to sustain these values has brought about the experience of poverty in all ramifications.

The continent of Africa which is endowed with both material and immaterial resources capable of ensuring development is now a place that is ridden with crisis of poverty. The bane of poverty, lack, and hardship has been hinged on two forms of forces of change; the first one has a connection to the historical happening brought about by colonialism. This ushered in unbridled economic exploitation and sapped sub-Saharan cultures of their vitality (Abraham, 1992). However, the second force, which is internal, is associated with corruption, mismanagement and bad leadership, the effect of which is seen on the living condition of the people. Our effort here is not a mere glorification of the past by making reference to some core African values, but it is an attempt to critically examine and argue for a revisit of these values which are capable of promoting the humanistic views of the traditional culture.

In this work, effort is made to critically examine these forces of change, identify the missing link and suggest the way towards regaining those core values capable of restoring social order in Africa communities. In doing this, John Rawls Difference Principle is adopted as a theoretical framework. This principle is found capable of ensuring that benefits and burdens are fairly distributed for the advantage of every one, and more importantly the less fortunate in society. This would enhance the attainment of a stable social order and promotes the ideals of reciprocity, fraternity and brotherhood in the contemporary African society.

\section{The Nature of Traditional African Society}

One important way to open any discussion on Africa is to first understand the nature of traditional African society. In doing this, Professor Osaghae (1989) has put it succinctly that:

Typically, the unit of African society was the village community which was a system of production without classes because of the low level or lack of specialization and variety in the economy; based on undifferentiated social institutions; based on joint ownership of the basic property (land) and based on the unity of the whole community (groupism) rather than individuals (individualism).

Given the above descriptions of the nature of Africa society, it has been argued that these characteristics were not to be seen as peculiar to Africa but were true of all traditional societies the world over. It should be noted that universally, village communities emphasize the unity of being, existence and nature. In Platonic mode of thought, object of existence are seen as unity with essential realities to the end that each individual may become a fully developed moral being. In essence, the point here is that meaning and purpose as prescribed by Plato are to be found in a state of harmonious unity.

Senghor, in a more specifically African way, states that in traditional African society, the individual feels and thinks that he can develop his potential, his originality, only in and by society, in union with all other beings in the universe: God, 
animal, tree or pebble (Senghor, 1975). The point we are making here is that, human communities emphasize the unity of being, existence and nature. It is a universal phenomenon in which Africa is not an exception.

Most institutions of the pre-colonial African societies were well developed before colonialism. The political system were classified as centralized and non-centralized (Fortes \& EvansPritchards, 1946). In the non-centralized system, there was no government in the modern sense of it, there was a picture of egalitarianism and differences in rank or wealth was not well pronounced since political office did not confer on the holder power over the community's surplus or over the loot from war. However, the centralized systems had state structures and cleavages of wealth, privilege and status which corresponded to the distribution of power and authority. In this system the distinction between ruling classes and oppressed classes had emerged.

Other institutions also include religion and the judiciary. Religion served to ensure that duties were as moral obligation, carried out, and sanctions were imposed against the deviants. Religion controlled conduct, it gave support to laws and customs, thus solidarity was based on conformity. Although, by implication, the individual's freedom of thought and initiatives were limited, any form of disloyalty to the community was believed to endanger the common existence. The institution of justice was equally not primarily to assess the relative rights and wrongs of a case, but to re-establish unity in the community. Punishments were carried out against law breakers, ranging from excommunication from rituals and banishment. Above all was the economic institution, which is central to our discussion on poverty in this paper.

The major means of production in most traditional Africa was land and this was communally owned and held in trust by the rulers for the community. Every member of the society, had a right to land, thus equality and common ownership mutually reinforced one another. Following Nyerere's view:

There was an acceptance that whatever one person had in the way of basic necessities they all had; no one could go hungry while others hoarded food, and no one could be denied shelter if other had space to spare. Within the extended family, and even within the tribe, the economic level of one person could not get too far out of proportion to the economic level of others (Nyerere: 1960).

The above description of the communal living is what Nyerere conceives as the socialist achievement of pre-colonial Africa and the values being attached to it by the people. He noted that the traditional society was a disciplined one. According to him, every member worked to earn a living, the tradition of hospitality which was an integral part of African way of life does not even allow a guest to remain idle. The Swahili proverb, which has the status of an injunction: "treat your guest as a guest for two days; on the third day give him a hoe!” was indeed the very basis and justification of the socialist achievement of which the people were proud of.

Moreover, Nyerere noted further that;

One of the most socialistic achievements of our society was the sense of security it gave to its members, and the universal hospitality on which they could rely. But it is too often forgotten, nowadays, that the basis of great socialist achievement was this: that it was taken for granted that every member of society-barring only the children and the infirm-contributed his fair share of effort towards the production of its wealth (Nyerere, 1960).

The main issue here is that, reciprocity and hard work is what characterizes the economic system of most of the traditional African society. Meanwhile, it should be noted that traditional society was however, not problem free, neither were the conditions idyllic but the main point that interest us is the fact that the value of reciprocity and togetherness made the issue of poverty unacceptable features in the traditional community.

Following the above discussion, the concept of reciprocity remained a core concept in social practice in Africa. However, some notable philosophers, namely Hobbes and Hume contributed in writing to the concept of reciprocity, while reflecting on the issues facing Europe in its transition from a pre capitalist to a capitalist society (Hyden, 1990). Although, the challenges post by modernization had the tendency of regarding the concept as part of a historical phase already passed by humankind and an attempt to interpret it as over glorifying the African's past. This notwithstanding, a renew focus on reciprocity is still relevant and significant.

Reciprocity as a concept is often compared to the concept of exchange (Blau, 1972), both concepts refer to interactions consisting of mutually beneficial transfers. An exchange is fully contingent relationship: each part agrees to perform only on condition that the other performs. Similarly, exchange is also assumed to exhibit simultaneous performances between parties. The exchange is conceived as a single event in which there is no doubt as to whether one will receive as well as give. However, a formal definition of reciprocity can be termed as a mutual transfer; in this regard it is the contribution that each party makes to the welfare of the other that generates an expectation of mutual performance. Thus, reciprocity occurs only if these expectations converge. Reciprocity affords individuals to contribute with a single act to the welfare of numerous others and sustain expectations of mutual return. It is this interaction that promotes the economy of affection and makes individual to contribute with an expectation that others will do likewise.

In the Africa traditional setting, reciprocity develops largely due to the situation where each person lives close to the margins of survival and believes he does not possess the means to survive a hard year on his own. So, therefore, making a contribution to somebody else or to the community at large with the expectation of receiving something in return at some later point seems sensible in such circumstances. It is against this background that James Scott refers to this kind of behavior as the "moral" economy. His main argument centered on the fact that peasants are risk averse and as a result has collectively developed social insurance mechanisms (Hyden, 1990).

The above discussion is simply that, reciprocity as a concept, which has to do with exchange and interaction among the people has its relevance in the traditional African society. Its role in relating community to state, institutionalizing of rule, improving public management and enhancing social justice cannot be undermine. Moreover, similar to the concept discussed above, which added value to the African Traditional society is the concept of fraternity and brotherhood. These, like reciprocity, promote friendship and further strengthen the bonds of family hood. Nyerere's doctrine based on the communal structure of African society buttressed this further. In his Ujamaa: the basis of African socialism, Nyerere claims that the social structure of 
African society is basically an extension of the family unit, conceived as an integrated "organism". Our recognition of family to which we all belong must be expected yet further beyond the tribe, the community, the nation, or even the continent-to embrace the society of mankind (Nyerere, 1969). The foregoing idea presented by Nyerere has come under a serious attack, arguments have ensued on how such a proposition can be correctly conceived, let alone justified (Eruvemba, 1981). Yet, the point to be noted here is that Nyerere's postulation is to establish the claim that whatever is produced through land, tools and labor in such a fraternal society is communally owned by all members of the community. Hence, the social system has a way of making provision for all in the community, so that no one would be totally un-cared for.

Thus, following our discussion thus far on the traditional African society, it is clear from the foregoing that there were certain things that could be called cultural heritage, which made up the core values of the Africans. It is against this backdrop that we shall look at both the external and internal forces which brought about the predicaments of poverty, hardship and lacks that most African nations are experiencing in the recent time.

\section{The External and Internal Forces of Change}

It should be reiterated at this point that the problem of poverty and lack that most nations of Africa are witnessing is as a result of several factors, which are both external and internal. By the external factors, I mean those crises that emanates from direct colonization and all its contradictions, major among which was associated with the sovereignty of the Africa economy and after it neo-colonization with its weakening of the African states (Uroh, 1998). The internal factors majorly bother on the activities of leaders in corrupt practices, mismanagement and bad leadership.

Now, looking at the external forces of colonialism, Sogolo (1993) noted that, hardly would any writer on contemporary issues in Africa today proceed without relating whatever he has to say to the colonial experience of the African people. The reason adduced for this, center on the premise that the present Africa would not be what it is today if the colonial phase of its history were erased. Although, one cannot, however, say with certainty what the present state of affairs could have been, perhaps not beyond the vague speculation that at least the economy of the continent, its political system and, indeed, the sociocultural institutions would have been different. My aim here is not to go into details on the subject of colonialism since much work has been done in the literature (Rodney, 1972). However, it should be pointed out that colonialism has affected traditional culture in many irreversible ways

According to Williams Abraham (1992):

Colonialization ushered in unbridled economic exploitation and sapped sub-Saharan cultures of their vitality. They become deprived of direction and internal impetus, and increasing survived as pageant and ceremonial. New ideas concerning individual accountability and individual vision and the ascendancy of self-interest in contrast with community interest as a basis of action, the growing sense of private power arising from self-action rather than clan direction , all of these atomising factors, acting in concert, have loosened the internal bonds and efficacy of linagebased clan (Abraham, 1992).
The above submission as presented by Abraham depicts the realities of the economic situation of most African nation in this contemporary period. Colonialism thrust Africa into the world capitalist system dominated by metropolitan forces that operated under harsh individualism, "and by so doing created" a new world (economic) order in which Africans were ( and still, are) ill-equipped to compete (Uroh, 1998). The first change to be noticed was that there was a reorganization of the economy by the colonial powers. Take for instance, cash crops like cocoa, coffee and groundnuts were introduced, and attention thus was shifted from the production of food crops to cash crops and the implication of this was the emergence of scarcity and inadequacy of locally produced foods, hence, the rise in the bill for imported food items. Here began the emergence of economic poverty, having in mind the antecedent of slave trade which has depleted African population with its effect on the economic activity both directly and indirectly.

With the introduction of cash crops, African economy then became dependent on the economy of the West. This is because cash crops could not be easily processed into finished products and as a result of that, African countries had to search for market abroad. The continent of Africa thus faces a difficult situation in its economic relations with the developed countries. This relationship has kept most African nations under a perpetual crisis and disadvantages till date, and the ultimate consequence of this has made the economic situation of most nations becomes a consumer of what it does not produce. According to Oladipo (1998), the colony was simply a place where the colonizing power found it convenient to carry out some of its business. Hence, economic relationship between it and the metropole was conceived in terms of an exchange of Africa raw materials and markets, on the one hand, and European industrial good on the other. In other words, the colonial economy was essentially organized and managed to service metropolitan needs. The point here is that, for the battle of economic freedom to be won, there must be a return to some basic cultural values which are capable of making Africa nations to develop and overcome the present problem of poverty.

Now, coming back to some internal forces, the problem of poverty, hunger and lack in most African nations have been linked to the negative political and corrupt practices of the political leaders. According to Ujomu (2002) corruption and mismanagement of the economy have led to the paralysis of every sector of nation's life, for instance, social service, manufacturing, agriculture, etc. This situation has created a fertile ground for conflicts in the country, owing to the fact that the needs, hopes and expectations of the bulk of the citizens for security, prosperity and well-being, have not been adequately met.

Notable among the causes of poverty is the issue of political corruption associated with most political office holders in Africa. According to Gyekye, (2003) political corruption is the illegal, unethical and unauthorized exploitation of one's political or official position for personal gain or advantages. The word political is intended to refer to public affairs: the official goods, affairs, fortunes, agencies, resources and institutions of the state which is a human community with organized, public institutions. There is no doubt that corruption is the bane of development in third world and the effect of this has made the condition of living perpetually backward.

According to Oyeshile (2000), corruption has almost become a way of life in Nigeria; it is the bane of development and a 
major cause of social conflicts. To this end, it should be noted that the negative effects, which corruption generates are evident in Africa. Some of the effects includes; erosion of public trust, allows incompetence, it delays all forms of economic intercourse, thereby boosting costs and diverting energies to the concealment of private gain (Ujomu, 2002). These, without doubt culminate in abandoned project, poorly maintained roads, lack of good health facilities and inadequate funding of educational institutions.

Our position here is to reiterate that the failure of African leaders, both civilian and the military counterpart, due to corruption and mismanagement of the public funds has further worsened the precarious conditions of the people in Africa. Thus, the problem facing most nations then become compounded, it is both external and internal.

\section{A Critical Examination of the Forces of Change and Reflection on Rawls Difference Principle}

Following the analysis of the forces of change as presented above, the questions that arise at this stage are numerous: Is there anything inherently wrong with Africa that the continent has remained untransformed ever since independent? Why is it that the rapid development taking place in other continent of the world are not visible in Africa? Is Africa doomed for failure? And what philosophy should Africa adopts that can facilitate the development we need?

An attempt to provide answers to these various questions would afford us the opportunity to briefly consider the views of some scholars who have reflected on this issue relating to how to achieve development in Africa. Following the summation made by Oladipo (2009), some African scholars have argued that the way to cure Africa of her cultural problems, more importantly the economic problem that led to poverty is through the reclamation of pristine Africa traditions and customs (Oladipo, 2009). Such scholars preach a certain kind of "reafricanisation", and their opinions is on the premise that there are certain values which are considered to be distinct from (though not inferior to) Western values and ways.

This commitment to the revival of Africa culture as argued could be a step in the right direction. In this regard, this may be one way by which Africans can develop the capacity to correct some of the socio economic problems that arise from the forces of colonialism. Oladipo (2009) noted further that the development of a universal African consciousness would therefore be a means of undermining the socio-economic basis of the colonialist or racialist denigration of the Africa personality. It would also provide the condition for generating the self confidence, which is a precondition for the achievement of self-directed change in Africa. The point here is that the hope for the socio economic reconstruction of Africa is attainable if the cultural values can be revived.

However, some other African scholars are of the view that since there have been changes as a result of contact with other societies, that what Africans need today is a break with their cultural inheritance, which they find deficient in some fundamental ways. This position as Oladipo (2009) maintains, is based on the observation that change is an inescapable aspect of the human condition and that no society can develop in contemporary times without science and technology which is the hallmark of the exposure to the force of Western influences.

Having considered the views of these schools of thought, the fact remains that on the one hand, there are certain core values that are germane to solving the socio economic problem in Africa while on the other hand, there is the need to embrace some Western values such as science and technology without which there can be no significant socio cultural and economic development in contemporary Africa. Here comes the middle ground, which recognizes the fact that continuity and change are interwoven aspects of human experience. This is what some notable African philosopher called cultural synthesis (Oladipo, 2009).

In view of the above, the hope of arriving at the lasting solution to the problem associated with those who are poor in relation to the social, economic, political and mental goods in Africa seems not totally loss. Poverty, as the World Bank (1990) defines it goes beyond having no food on the table, it includes: "the inability to attain a minimal standard of living". In the same vein, according to Albert and Agwuwah Nkwazena (2002), poverty is a severe lack of physical and mental well-being closely associated with inadequate economic resources and consumption.

Following this, the above definitions suggest that poverty exists when people lack the means to satisfy their basic needs .Therefore, for this particular problem to be reduced to the barest minimum in Africa, here comes the relevance of Rawls Difference Principle, an economic principle that is capable of ensuring that benefits and burdens are fairly distributed for the advantage of every one, and more importantly the less privilege. This would enhance the attainment of a stable social order as it promotes the ideals of reciprocity and fraternity in society.

John Rawls in his Theory of Justice presents two principles of justice. The first of these two principles is mainly about rights and liberties and the second about the distribution of social benefits. It is this second principle which is called the Difference Principle. Rawls believe that there are certain primary goods that all men presumed to want as a rational being (Rawls, 1971), the primary goods fall into two main categories, namely primary social goods such as right and liberties, opportunities and powers, income and wealth; and primary natural goods such as health, vigor and intelligence. Rawls considers these goods as being very basic for living a meaningful life. For Rawls, a just society is one in which these basic goods are to be distributed to the advantage of each members within the society.

The difference principle implies that a just economic system distributes income and wealth so as to make the class of the least advantaged person better off than would be under any alternative economic system. So, social institutions are to be arranged so as to improve the position of those who are least favored as regard the basic primary goods, Rawls' view is that the difference principle proffers solution to the problems of distributive [economic] justice.

Central to Rawls view is that unequal distribution may still be just in so far as it is to everyone's advantage. Injustice to Rawls is not simply inequalities per se, but "inequalities that are not to the benefit of all". What constitute injustice are the excessive expectations of the well off. For him, therefore, a maximum just scheme would be one which decreases the excessive expectations of the privileged while increase the lot of the less privileged. To Rawls, the expectation are "chain connected", that is, the fact that the worst off in the society would become better off, does not imply that the better off will be 
cheated, or be made worst off but their own position would also improve compare to the initial position. Thus, the principle does not involve in the elimination of the advantages of those that are well off. It protects these advantages in so far as doing so helps to ameliorate the lot of the less fortunate. This is the sense in which Rawls principle involves reciprocity and mutual benefits.

However, one major significance of Rawls difference principle is the concept of reciprocity. This is a principle that promotes mutual benefit among the people in the society. John Rawls believes in a society that promotes the welfare of all, with more emphasis on the least advantaged. According to Rawls, the well being of everyone depends largely on the scheme of social cooperation without which no one could have a satisfactory life. In this regard, reciprocity as a concept promotes good relationship and expands the scope of interaction.

Following the above, the idea of reciprocity as being conceived by Rawls promotes mutual bond among the people in the society and as well facilitates the desire to better the lot of one another. This concept would go a long way in ensuring that benefits and burdens are distributed to improve the lots of the least advantaged ones and consequently reduce poverty in the contemporary African societies. It should be noted that the less fortunate are usually the majority at least here in Africa. They form over 90 percent of the population, following the view of Oruka (2000) therefore, it is fitting that they are given priority.

The question that may readily come to mind here is how would these concepts of reciprocity and fraternity become practicable, considering the challenges of capitalism which promotes individualism in the contemporary Africa society. To Rawls, justice is the basic structure of the society, and this basic structure is for creating the means by which benefits and burdens will be justly distributed. Hence, the structure that would create the platform on which basic primary goods which all men desire to have would be distributed is the crucial point where the state becomes relevant in this discussion.

There are major key institutions of the society that should be strengthened for effective distribution of benefits and burdens for the advantage of the poor in the society. The very first and most important is the institution of leadership. Leaders with vision, clear sense of purpose and mind for service towards ensuring the well-being of the people are qualities needed at this crucial moment when Africa is in dire need of development. A leader that is democratically elected with a good sense of morality would be such that can guarantee a stable social order.

In addition to the above point is the need for the establishment of the institution of social welfare system. This, as a matter of urgency is needed to be given appropriate attention if poverty is to be tackled in Africa. The social welfare system is meant to cater for the basic security and the well being of all the members of the society. In a welfare state for instance, the government is concerned with public health, unemployment, provisions of basic amenities and adequate care and support for those who are handicapped and lacked the privileged to earn a livelihood.

Thus, the multifaceted nature of poverty in the continent of Africa demands a multidimensional approach to solving this all important problem. It is against this backdrop that this paper is strongly advocating for a revisit of some core values which promotes interactions, mutual bond and common interest. This value would go a long way to improve the standard of living of every one in society, promote unity and togetherness and con- sequently sustain human dignity.

\section{Conclusion}

In this paper, efforts have been made to critically examine the issues of poverty in Africa, in doing this, the paper analyze the nature of traditional African society. Certain core values such as brotherhood, fraternity and reciprocity were discussed as what made Africa and its people self-sufficient in the generation and distribution of the basic necessities of life. However, two forces of change were identified as the bane of poverty in Africa; the first one is external forces of colonialism, which ushered in unbridled economic exploitation and sapped subSaharan culture of their vitality. The internal forces have been linked to the negative political and corrupt practices of the political leaders. This work, having critically examines the implications of poverty in Africa, argues for the application of Rawls difference principle. This is an economic principle that is capable of ensuring that benefits and burdens are fairly distributed for the advantage of all, and more importantly the less privilege in society. However, the major key institutions that would be needed for effective distribution are to be put in place. Consequently, this principle would enhance the attainment of a stable social order, as it promotes the ideals of reciprocity, fraternity and social interaction which are the core values required for the economic empowerment in this contemporary Africa society.

\section{REFERENCES}

Albert, I. A., \& Agwunwah-Nkwazema (2008). Gender conflict and poverty in West Africa. Journal of the Institute of African Studies, 80.

Blau, P. M. (1972). Social exchange, international encyclopedia of the social sciences. New York: The Macmillan, 452.

Eruvemba, J. T. (1985). The concept of African brotherhood and praxis of unity: Nyerere revisited in philosophy in Africa trends and perspectives. Ile-Ife: University of Ife Press, 196.

Fortes, M., \& Evans-Prichard, E. E. (1946). African political system. London: Oxford University Press, 21.

Gyekye, K. (2003). Political corruption: Aphilosophical inquiry into a moral problem. In Philosophy and politics, discourse on values, politics and power in Africa (p. 395). Lagos: Malthouse Press.

Hyden, G. (1990). Reciprocity and governance in Africa. In The failure of the centralized state institutions and self-governance (p. 253). Oxford: Westview Press.

Nyerere, J. K. (1960). Ujaama: The basis of African socialism. Oxford: University Press, 107-108.

Oladipo, O. T. (2009). Philosophy and social reconstruction in Africa. Ibadan: Hope Publication, 18.

Oladipo, O. T. (1992). Freedom and culture: The African experience, praxis international. A Philosophical Journal, 12, 205-214.

Osaghae, E. (1989). The passage from the past to the present in African political thought: The question of relevance in African traditional political thought and institutions. Lagos: Centre for Black and Africa Arts and Civilization, 54

Oruka, O. S. (2000). Critique of rawls in the philosophy quest: A crosscultural reader. McGraw Hill Inc., 610

Oyeshile, O. (2000). Corruption and underdevelopment in Nigeria”. RECALL: A Chronicle of Nigerian Events, 1, 55.

Rawls, J. (1971). Theory of justice. Harvard: University Press, 62.

Rodney, W. (1972). How Europe underdeveloped Africa. Dar-es-Salam: Publishing House.

Tanzania Senghor, L. S. (1975). A prerequisite: Cultural independence in Readings in African political thought. London: Heinemann, 599.

Ujomu, P. (2002). Social conflicts resource distribution and social justice in Nigeria. Journal of Asian and African Studies, 63, 197-228.

Uroh, C. U. (1998). Situating the challenge of development in Africa. 


\section{O. ADERIBIGBE}

Ibadan: Africa and the Challenges of Development, Hope Publication,

Uroh, C. U. (1998). Beyond ethnicity: The crisis of the state and regime legitimation in Remaking Africa, challenges of the twenty-first cen- tury. Ibadan: Hope Publication, 98.

William, A. (1992). Prologue: Crisis in African cultures, in Person and community: Ghanian philosophical studies 1. Washington, DC: The Council for Research in Values and Philosophy, 27. 